\title{
Just-in-time open and distant training offers must match market and learners requirements
}

\author{
Michel Arnaud \\ Researcher, CNED Research Laboratory on Knowledge \\ Industry, Téléport 4, Asterama 2, BP 300 \\ Avenue du Téléport, F-86960 FUTUROSCOPE CEDEX \\ Tel: + 335 49493468; fax: + 33549490584 \\ Email: michel.arnaud@cned.fr
}

\begin{abstract}
The European project METASA (Multimedia European Experimental Towns with a Social-pull Approach) has sought to involve citizens as partners in the development of the information society and to demonstrate telematics applications for specific domains: administration, employment, education/training, health care and leisure/entertainment. After a careful analysis of citizens' expectations in the four small towns involved, Arnedo (Spain), Parthenay (France), Torgau and Weinstadt (Germany), which was done by a team of social researchers ${ }^{1}$, education and training not surprisingly appeared as a priority for citizens to get acquainted with the new communication tools and to meet the challenges of the postindustrial society where everyone has to adapt continuously to the requirements of an ever-evolving job market.

Because patterns of learning are changing, because adults do not have long time periods available for study, and because they may have problems studying alone using communication tools, training processes are to be customized to their special needs: flexibility in schedules, and adaptability in content. Distance training offers have to be designed to reach learners where they are and when they are available, which means taking into account their time constraints, remedying their media-related cognitive hurdles and, in fact, developing a new continuing school paradigm. To build a just-in-time approach satisfying both employers and learners needs, educational content designers must work in a coordinated manner with employers and training administrators to prepare learners through adequate
\end{abstract}


training so that they can acquire the professional skills and competencies needed for them to apply for and get jobs. Knowledge centres (to accommodate learners' time constraints) and knowledge exchange networks (to compensate for the asynchronous/synchronous difficulties of communication tools' use) are two aspects of the new continuing education set up to meet the challenges of the information society.

\section{INTRODUCTION}

For the last twenty years, resource centres for distance learning in France and in Europe have come up short in providing adequate services. One of the reasons for this failure may be that they were not designed according to a bottom-up approach: learners' needs were taken into account only through a typology that reduced them to stereotypes. To define learners' needs requires considering them through a fullscale analysis of learners' life conditions; personal background, history and social setting are important factors shaping reactions to a knowledge transmission and building process.

The METASA project has offered us the opportunity to apply this approach through the study of four small towns and their citizens' needs. The definition of the METASA project came out of a 'political vision - local democracy, underpinned by a theoretical orientation - local particularity combined with general integration, and by an economic purpose - fostering of sustainable development ${ }^{2}$. The METASA project has sought to develop a 'social-pull' instead of a 'technical-push' approach, by allowing citizens to participate fully in the development of the information society and by aiming to demonstrate applications for economic actors (small-medium enterprises, micro and single-person enterprises, local commerce and crafts). By concentrating totally on users' needs, it has chosen therefore to focus on improving quality of life and on developing specific application domains: employment, education/training, health care, leisure/entertainment and administration.

Although each of the four METASA towns has its own socio-demographic and socio-cultural characteristics, it seems possible to draw from the report on users' needs written by METASA social science researchers, a common hierarchy of expectations linked to the development of local socio-economic systems, based in particular on the analysis of users' socialization and relationship to technology. Education and training not surprisingly appear as a priority for users to get acquainted with the new communication tools. To restrict social exclusion, training offers have to be customized not only for computer-literate users but also for beginners. This approach takes into account the whole population. It is based on a market segmentation, designed first to cater to potential service purchasers' needs but also to include progressively other users. It takes into account their expectations, in order to build extensive and therefore economically and socially viable services. 


\section{EDUCATION AND TRAINING REPRESENTED NEEDS}

Users understand what is at stake, constraints are correctly perceived as well as opportunities. They see how positive and negative factors may influence their decision to use or not to use these new communication tools: they may start using them if they feel that benefits drawn from their usage compensate for hurdles they encounter when trying to use them. They are afraid that more jobs will be lost because of the information society and that new communications tools will be reserved for the happy few able to pay for them. In order to keep control of local social evolution, a willingness to be informed and to be part of the decisionmaking process at each project phase is clearly expressed. Students as well as adults ask to be consulted regularly: their remarks must be taken into account, they want a users' group to be part of the METASA steering committee.

The opinion survey undertaken by METASA social science researchers has shown the importance of education and training needs in relation to technology. Although the same pattern appears more or less in the four METASA small towns (Parthenay, Arnedo, Weinstadt, Torgau), we have chosen Parthenay's population as the most significant as far as users' mental representations are concerned. Not surprisingly, the users are aware of structural changes needed in schools and educational institutions in order to match emerging training challenges: new communication tools cannot be used in a traditional classroom, teachers not only have to master them but must change their pedagogy.

Basic training for every learner is a first requirement. In order to help teachers, who are certainly not numerous enough to respond to this global basic training demand, tutors are to be made permanently available as local help in public resource centres. They help to achieve this computer literacy objective, making it possible to improve access to information for all, and therefore to provide efficient public online services. Although the teacher's role seems more than ever crucial for a proper knowledge transmission process, self-training is seen as a means of completing whatever face-to-face contacts with teachers can be secured.

Potential users also stress that distance learning must be developed as well as public resource centre access. In order to facilitate the preparation of exams through distance learning, knowledge exchange networks should be fostered. Youngsters should be trained as a priority, not only to fight against their dropping-out of schools but also to open up new study opportunities through the promotion of foreign language learning, thereby multiplying study options, school networks, and teachers and students at national and international levels. Adults should benefit from the development of professional training tools, bringing enterprises and the educational system closer, with facilitated access to data banks on job markets and information on local and global economic activities. Services development should lead to the setting up of training servers with adapted tools for learning, professional orientation, accreditation of prior learning (APL), and job offers.

\section{THE KNOWLEDGE CENTRE PROJECT}

We think that we could avoid the failure of our cooperative concept of knowledge centre by choosing a new approach, taking into account factors which have usually 
been excluded from needs analysis. Three areas seem of interest to us as potential roadblocks on the path of learning: making time available for study versus constraints such as transportation, family chores, etc., overcoming media-related cognitive hurdles as they exist in distance learning, and getting appropriate training for a specific job.

Three changes are to be implemented in various aspects of a classical resource centre: facilitated access to knowledge centres, appropriate tutoring and knowledge exchange network, customization of learning modules to the requirements of the job market and learners' levels. As we expect problems and resistance, this project action plan has been designed with an integrated logistic cycle and a transverse collaborative approach so that the project steering committee can respond immediately and propose solutions. In our knowledge centre, indicators will measure the accuracy of our hypotheses during the implementation steps, by keeping track of attendance, examination result, and job entry or re-entry rates compared to more traditional resource and distance learning centres.

\section{Facilitated access to knowledge centres}

The concept of a knowledge centre aims at responding to potential learners' needs by offering a space where it is possible to seek information, education, and entertainment. The goal is to meet the general request for job market flexibility, lifelong learning, and leisure activities. It is a place where people should keep coming during their entire lives, to prepare for a new professional activity or at least to brush up their skills.

\section{Helping learners to overcome time constraints}

The first obstacle is a general lack of available time to devote to study. This is observed with a majority of potential learners. In fact, learning patterns are changing: learners do not have long time periods available for study, unless they can get specific leaves or have not found a job. According to this approach and to make access as easy as possible, knowledge centres are to be set up in towns as well as in rural areas, to be open all day long and late at night, with kindergarten, cafeteria, administrative and technical staff who can provide guidance and social help when needed. Practical aspects of day-to-day life have to be handled or facilitated while attending sessions at these centres, so learners can concentrate on knowledge acquisition processes within specific time spans.

\section{Mixing learners to promote convivial exchanges}

It appears necessary to offer a constant opportunity to meet similar as well as different people in knowledge centres. They are to be made accessible to all sorts of potential learners. For the convenience of our study, one can classify this population into three categories that can overlap: schoolchildren and students, adults eager to acquire general knowledge, and adults in professional training. Information, education and entertainment offers vary according to targeted audiences. Different types of paths are offered according to individual needs and potentials, in a graduation of increasingly specialized hard knowledge or soft knowledge (where social practice and interpersonal exchange are more valued). 
Schoolchildren and adults in a quest for general knowledge have need of knowledge acquisition and construction, linked to the school curriculum, for example; the latest developments in the technical and scientific research field; environmental issues; and new technical tools. Local schoolchildren, that is to say college students as well as school pupils, will be able to use a knowledge centre to learn rarely taught foreign languages through videoconferences, access data bases via the Internet, and so on. Another category of learners in the knowledge centre wants to follow appropriate training in order to improve job qualifications. All these persons may benefit from a desire to learn they can share while exchanging information on specific subjects of interest. This hypothesis needs of course to be verified.

\section{Unique service window for the socially isolated}

Another segment of the population, the underprivileged and socially excluded, should also be invited to come to knowledge centres. It is not appropriate to hide the fact that the socially excluded show little interest in the new communication and information technologies. They have suffered too much already in being offered gadget solutions to their problems, and they have been treated as pawns in hightech deals by hardware merchants with local authorities. We understand their first reaction of distrust when confronted by our offer. The only way to turn around the situation is to offer all kinds of social assistance in knowledge centres concentrated at a specific administrative window, in order to solve social problems as much as possible, so that this kind of learner can concentrate on his or her practice and quest for knowledge.

\section{Appropriate tutoring and knowledge exchange network}

Traditional knowledge building for learners seems to conform to teachers' injunctions and dogmas. This process sometimes results in learners being living replicas of their teachers. Repetition and evaluation exercises are mainly used to verify knowledge acquisition processes in traditional classrooms. In this context, schooling failure occurs as soon as the master-pupil relationship is scrambled by too great a number of pupils for a single teacher, when what is taught is too far from practical cases to be solved in job situations, or when too long a period of study is required to get a degree. In knowledge centres, the learning context is more flexible: learners can study alone, in groups with or without a tutor, participate in videoconferences, or use email to be in contact with teachers. Because of teachers' scarcity, constant evolution of knowledge fields and learning needs considerable expansion. Learners' autonomy that is greater than in traditional classrooms has to be promoted.

\section{Compensating for media-related cognitive hurdles}

The role of a traditional teacher can be divided into four in the context of education and training in a knowledge centre: he/she is the designer of multimedia courses to be used by learners alone or in groups, an expert available at a distance (through telephone and videoconference) for specific classes and remedial activities, an animator for telematics exchanges (forum, email, etc.) and, finally, a tutor-mediator in a context of hybridization of face-to-face and distance teaching. An important 
effort of customization of multimedia design is to be made because distance learning devices can disturb the traditional way of learning ${ }^{3}$. In order to compensate for this handicap, specific skills have to be developed by learners. Therefore, pedagogy is less a knowledge transmission process than a way of inculcating methods to learners so that they know how to identify proper information, and to classify it and integrate it within their own knowledge representations. The expert teacher, who is available at a distance, intervenes by telephone or videoconference: his/her role is to give exact references for the knowledge content and to stimulate learners in live sessions. The animator of the telematic system uses email and forums to discuss issues with learners, to answer basic questions (those most frequently asked) and to pass on the ones he/she cannot answer to the distant teacher-expert who is the specialist in his/her field.

\section{Knowledge exchange network boosting learner confidence}

Knowledge exchange networks are to be used as a mean of intensifying exchanges between learners. The objective is double: to unlock those who have failed at school and to create a mutual desire to learn. Knowledge content exchanged in a network is usually basic training in maths, literature, etc. as taught in a secondary school. If successfully done, this exchange can constitute a solid brush-up of the basic knowledge required to go further in any specialized training (' $I$ teach you cooking, you teach me arithmetic' and so on). The principle on which a knowledge exchange network functions is that you can be taught only if you teach something to someone else. It does not have to be the same person. The mediator's role is to identify the learning needs of each of the participants and the domains in which they know something that is in demand to be learned by others. The first step is to identify who is in need of teaching, and who can share his/her knowledge and then constitute a network of pairs in order to regulate the exchanges. An important side-effect of this process is that the person who is teaching realizes that he/she is worth something since he/she teaches something to someone else. It is more likely, although it has to be substantiated by further research, that an apprentice teacher involved in a knowledge exchange network will be inclined to search for additional information if challenged on a specific subject. Furthermore, he/she may go back to study with a more relaxed, although more organized, learning method.

\section{Appropriate tutoring absolutely needed}

The mutual desire to learn can be boosted if there is a clear linkage between the knowledge acquisition process and the social behaviour of the learner that is commonly shared in knowledge exchange networks. Therefore, the external and internal system of tutors and mediators within the knowledge centre has to convey a specific behaviourist model of knowledge access which is as informal and as friendly as possible. It is not our intention to diminish the role of the teacher who should remain, more than ever, the reference point in terms of knowledge and, most of all, must show how to retrieve the proper information, validate it and help in the process of assimilating it. Facilitated access to face-to-face tutors is also to be provided according to our analysis, in order to avoid discouraging learners confronted with a teacher at a distance who is inevitably more difficult to 
understand. To study in a group with the help of a tutor-mediator can therefore remedy the abruptness of synchronous distance training if proper pedagogical content and methods are used. Less than knowledge providers, tutor-mediators become models, conveying values of social exchange and communication, paying great attention to learners' needs, making themselves available as often as possible. They must be successful in unlocking learners' potential, restoring their selfconfidence, and showing them an approach to knowledge made of self-respect: the ones who do not know should not be ashamed, because they know something on which they can build further knowledge and therefore they will soon compensate for their ignorance.

\section{Customization of learning modules to learners' needs and job market requirements}

Modularity is an important aspect allowing the greatest flexibility in training offers. Educational designers have to segment content in short modules, considered as value units to be capitalized. Learners can organize their study time according to their own schedules, provided administrative schooling rules are flexible enough to accommodate various study paces and validate them.

\section{Discovery classes for schoolchildren and students}

Specific classes are to be organized for schoolchildren and students, during one or two-week periods, in knowledge centres on a given topic: astronomy, hydrography, etc. Their pedagogical objective is to bring learners to the scientific process of building hypotheses that they have to verify by measuring experimentation results. This leads to a knowledge acquisition process of trial and error supported by a network of domain specialists and a team of local animators and teachers who come with the students from their regular schools. Children and students can therefore get acquainted with methods of scientific investigation and be stimulated in their own discovery of specialized domains which will result in an overall knowledge increase for each of them. For schoolchildren and other general audiences, without limitations due to a required degree of knowledge, it is possible to offer scientific game applications based on multimedia simulations and experimentations in a knowledge centre. This necessitates important equipment in multimedia hardware and software (such as microcomputers, CD-Roms, network servers, connections to the Internet, and a cable/satellite reception site).

\section{Offering appropriate job-oriented training}

Can we bypass the assumption that no matching between job and training is really possible or effective? For us, adult learners are mainly stimulated by a job offer at the end of their training cycle. If we keep that in mind, it seems to us that open and distance learning (ODL) designers should be part of steering committees composed of decision-makers and employers, assessing job trends in a given job market based on economic forecasts, and taking joint policy decisions in order to create jobs in a specific area for various economic sectors. Can this type of coordinated action in a knowledge centre help learners to get adequate training ? If the answer is yes, ODL designers should try to shorten the production cycle 
starting from job forecasts so that corresponding training offers are ready when jobs are offered.

Within this framework, learning plans are to be customized to learners' specific needs. The necessary steps are the candidate learner passing through the accreditation of prior learning (APL) process to get an accurate list of his/her current competencies and identification of qualifications required from the description of the specific job envisioned. The matching process involves identifying specific competencies, needed to fulfil a position, to be acquired through the learning plan. To get an accurate and customized learning plan, segmentation of curriculum content in small modules is to be carefully designed within a framework linked to job capacity requirements through national vocational qualifications (NVQs) analysis type and learner profiles.

\section{Professional training plans}

Appropriate professional training plans have to take into account these two complementary approaches:

- translation in terms of learners' competencies of their learning path (where they are and where they want to go, taking into account job market trends): elaboration of their profiles, as diversified as possible, in order to integrate them in different professional and pedagogical paths;

- formatting of training content in various pedagogical modules according to a competencies grid analyzing skills and knowledge to be mastered when each module is successfully completed (knowledge, know-how and skills references, etc.), allowing better identification of what contents can best fit the requirements of the pedagogical learning path.

The determination of the individualized training offer should include the following steps:

1. Job offers to be selected

- selection of a group of job offers by potential learners (through a connection with employment data bases for example),

- analysis of requested competencies to fill these positions.

Once a job offer is identified, a study of its characteristics has to be translated into requested competencies, and defined from an official repertory such as NVQs.

2. Accreditation of prior learning (APL)

- with an online assistance system and a professional career counsellor, analysis of the applicant learner competencies,

- competencies analysis with an APL methodology should be used as prescribed by institutional bodies entitled to undertake this type of evaluation.

3. Training modules choice

According to qualifications required for a job that a learner would like to apply for, a choice of appropriate training modules is to be made based on analysis of competency references attached to them: what competencies will be gained by learners when they pass the final test.

4. Individualized training plan

According to the analysis of competencies to be acquired by learners and those which they possess already (as checked with APL), training plans have to be 
built in order to acquire needed competencies that learners lack at present and that they need to apply for specific job offers.

This original approach needs to be validated in pilot projects to be started soon.

\section{CONCLUSION}

The key point is to see how citizens can really appropriate the new multimedia technologies in innovative situations such as the ones we are developing. By trying to answer their specific needs related to job and employment, access to education and culture, and in creating new services in a social-pull approach, we hope that citizens will feel driven to participate and become actors instead of being passive consumers. The interest in dealing with small towns is that we can observe community interaction and try to promote it by appropriate communication channels based on personal relationships. Self-reliance can be a key to success: a citizen should be able to get information about his/her immediate surroundings as well the outside world and decide to act accordingly, creating and improving with others the conditions of their lives. The role of steering committees with citizens' representatives is crucial in keeping a social dialogue open in order to improve services that more adequately meet social needs.

As the METASA project was interrupted at the end of 1996, the implementation steps for our knowledge centres has had to be postponed. Nevertheless, it is our intention to continue with a future European project and the same partners. In the experimental phase, indicators will keep track of attendance, examination results, and job entry or re-entry rates, compared to more traditional distance learning centres. We will check to see if accommodating learners regarding their time constraints, compensating for ODL devices training disturbances through face-to-face tutoring, and customizing training content to job requirements, can be decisive elements in making our knowledge centres a success.

Distance learning can compensate for the handicap of living in a remote area, provided a strong tutoring service is available supported by knowledge exchange networks, and with adequate tools to talk with distant experts. The development of interpersonal exchanges in knowledge centres can help individuals to return to training and to consider it part of their lives. As a consequence of their professional skills enhancement, they may find new jobs and occupations, created for or by them. Knowledge centres that provide basic access to the information highways as a public service are the condition for equal opportunity for all.

It should then become possible to build networks based on mutual interests among learners within and between knowledge centres, contributing to the creation of competency chains through extended knowledge exchange networks, and developing an harmonious computerized citizenship connected to other citizens of the world. 


\section{REFERENCES}

Arnaud, M., Dubois, H., Fualds, V., Jaeckl, L., Missri, M., Perret-Clermont, A.-N., Perriault, J., Porte, L., Humanities, workpackage 4, research and evaluation, final report, CNED/LARIC, Poitiers, 1996.

Cesar, M., Time's role in peer interaction, International Conference 'Mind and Time', Neuchâtel, Switzerland, September 8-10, 1996.

EuroStudyCentres, Development and Implementation, EADTU, Milton Keynes, 1994.

Greenfield, P.M., Cocking, R.R., (Eds) Interacting with video, Ablex, Norwood, 1996.

Grossen, M. Pochon, L.-O., Learning mediated by computers: to what extent is it 'situated?, Workshop on Learning in Humans and Machines, European Science Foundation, Aix-en-Provence, September 21-23, 1995.

d'Iribarne A., Eveno, E., Lenz, B., Lopez, A., METASA (Multimedia European Experimental Towns with a Social-pull Approach) Research final report, workpackages 3 and 4, LEST, Aix-enProvence, 1996.

Perriault J., Synchronous and asynchronous media in an hybrid learning process: effect of time compression and expansion, Fifth Eden annual conference, July 8-10, 1996, Futuroscope Poitiers, France.

Shaw, A., Social Constructionism and the Inner City: Designing Environment for Social Development and Urban Renewal, MIT, Dept of Media Arts and Sciences, 1995.

1 d'Iribarne A., Eveno, E., Lenz, B., Lopez, A., METASA (Multimedia European Experimental Towns with a Social-pull Approach), Final Research Report, Workpackages 3 and 4, LEST, Aixen-Provence, 1996

2 d'Iribarne A., Eveno, E., Lenz, B., Lopez, A., METASA, ibid., p. 18

3 Perriault J., Synchronous and asynchronous media in an hybrid learning process: Effect of time compression and expansion, Fifth Eden Annual Conference, 8-10 July 1996, Futuroscope, Poitiers, France 